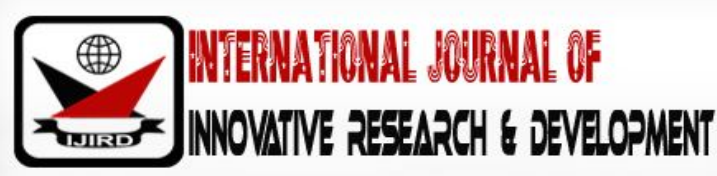

ISSN 2278 - 0211 (Online)

\section{A Critical analysis of Media Framing and Audience Framing: Comparing the "Media"and "Audience" Agenda in the 2015 General election in Tanzania}

\author{
Dr. Mwidima Peter Charles \\ St Augustine University, Tanzania
}

\begin{abstract}
:
The focus of this study was to explore the link between "media framing" and "audience framing". The main target was to examine if there is really a direct influence of the media on the audiences. To explore this, the study used the 2015 general election in Tanzania. Specifically, the study sought to know if there would be any similarities on the campaign agendas or issues covered by the media during the election campaign vis-à-vis those mentioned by the audiences. To explore the media agendas, a content analysis was utilized on eight (8) selected newspapers in Tanzania (the Guardian newspaper, the Daily newspaper, Uhuru newspaper, Mtanzania newspaper, Nipashe newspaper, Mwananch newspaper, Tanzania newspaper, and Majira newspaper). The units of analysis were all news articles or stories published on hard news, feature stories, and editorial comments whereby all campaign agendas published in the selected newspapers were recorded. Thus, a total of 84 campaign agendas were recorded after the newspapers review. Inorder to explore audience agendas, self-administered questionnaires were distributed to 667 respondents who were asked to list down all agendas that they knew during the 2015 election campaign. Since the respondents were the prospective voters who were registered in voters' registration books, a systematic sampling technique was used to get the 667 respondents. Both media agendas and audience agendas were coded, entered in SPSS version 20, whereby all necessary cleanings of the data were done. A simple frequency analysis was done on both sides to detect the link between media and audience agendas. Only top five agendas recorded from both sides were picked and compared. The findings revealed that there is no direct relationship between media framing and audience framing. In other words, the influence of the media on audiences is still questionable. This finding confirms that during election campaign, campaign rallies or meetings play a significant role (58\%) of information the prospective voters about party or candidate agendas or political manifestos whereas the media contribute very little (23\%) .
\end{abstract}

Keywords: Media framing, audience framing, pre-existing knowledge, emotions, political discussions, part affiliation, general election in Tanzania

\section{Background Information}

Media framing has been defined in different perspectives by various scholars as notes Lugalambi (2006) who says: "in the study of media framing, scholars have proposed several definitions for the concept, each either tending to emphasize a particular function or process". According to Oates, Kaid \&Berry (2010) media framing is a tendency of reporters to tell readers or audiences how to believe about (how to think about an issue), they decide what to write, or include within the view, or structure of a story and what to leave out. Reporters also decide what tone, words, and facts to include between and how to interpret issues in news stories.

Likewise, the concept of media framing has been referred to as a conceptual tool which the media, as well as journalists use to cover, interpret and evaluate information whereby the media sets the parameters in which citizens discuss public events (Seib, 2008). It involves the selection of aspects of some perceived reality to enhance their salience in such a way as to promote a particular problem definition, causal interpretation; it may slender the on hand political alternative (Seib, 2008, Wojdynski, 2008). Furthermore, media framing can be referred to the way events and issues are organized and made sense of especially by the mass media, media professionals such as journalists, editors and their audiences (Grant, Grandy \& Reesse, 2001). Rebecca (2005) defines media framing as a central organizing ideas or a storyline that provide meanings to an unfolding strips of events. The frames suggest what the controversy is about, and the essence of the issue.

According to Grant, Grandy \&Reesse (2001), media framing can be done by either a journalist or news editors. Despite 
the editors to let the facts speak for themselves, most journalists are accustomed to framing their news stories. Journalists are used to formulate the angles, frames or directions of the news stories in the mass media before even they interview sources, or collect other facts. They use frames as a central organizing ideas for making sense of pertinent events and processes. News and information in isolation can have little fundamental meaning, thus, when journalists report or write the news articles it helps to place facts into meaning context to provide coherence (Grant, Grandy \& Reesse, 2001). In most cases, it depends on the nature and purpose of the framing itself, but in most cases media framing can be done by journalists, editors or sometimes it can be initiated by sources of stories who may wish to frame topics to make information interesting and appetizing to journalists (Tangelo \& Kuyper, 2010). On the other hand, Pan \&Kosicki (1993) define audience framing as a schema of interpretation, a collection of anecdotes and stereotypes, which audiences, groups, and society, perceive, communicate, and understand about reality. In this process, people tend to build a series of mental filters through genetic and cultural influence. Audience frames as defined by Russo \& Schoemaker (2002) are mental structures that simplify and guide human understanding of a complex reality.

Furthermore, audience frames can also be defined as the kind of framing which is formed by audiences/individuals amongst themselves through discussions, interactions, and interpretations of issues around or exposed to them (Pan \& Kosicki, 1993). It is normally created or developed when audiences are exposed to a new environment, phenomenon, or to certain events such as plays, meetings, political campaigns, and many others. This definition is supported by Goffman (1956, 1974) who states that audiences normally create or build their own frames about an event (such as dreams, tests, fictional dramas) through sharing their diverse meanings and interpretations towards such as event. Normally their interpretations or definitions of the world are based on their biological, socially, cultural, or and economic backgrounds or experiences, and many other spheres of life (Goffman, 1974).

According to Pan \&Kosicki (1993), audience framing is done into two frames of references which individuals use to interpret and process information. First, they use global and long term political views and short term issue related frames of references. The global political views are results of certain personal characteristics of individuals and have rather limited influence on the perception and interpretation of political problems. Whereas the short term issue related frames of references can have significant impact on perceiving, organizing, and interpreting incoming information and or drawing inferences from that information. Audience frames usually occur when individuals decide to look for alternative sources of information (personal sources such as discussions, meetings, dramas, plays, forums, and so on). Apart from heavily reliance on the media, audiences or readers are also engaged in a process of information seeking which makes them look for more sources of information due to a general sceptical attitude towards sincerity of the media contents (Pan \&Kosicki, 1993). Receivers of political information are selective in exposure, reception, and perception. They are sceptical about the intent of the sender and keep processing individual frames in a society.

\subsection{Tanzania 2015 General Election}

The 2015 presidential election was the fifth election to be held in the country (Tanzania) since independence in 1961. It involved the election to choose the president of the United Republic of Tanzania, Members of Parliaments, and Ward Councillors. The election mainly was dominated by the ruling party Chama Cha Mapinduzi (CCM) against the coalition of the four main opposition parties of CHADEMA, CUF, NCCR, and NRA which were under the umbrella of UKAWA. It should be noted that during the 2015 election in Tanzania, the four main opposition parties united together and formed a coalition called "Umoja wa Katiba ya Wananchi” UKAWA [the union of citizenry constitution] whereby they agreed to have one presidential candidate who would stand for the coalition. At the primary election within the parties, the ruling party (CCM) was projected to elect the former Prime Minister Edward Lowassa as their flag bearer while the coalition parties were also projected to have Dr. Wilbroad Slaa as their flag bearer. Unfortunately this did not work out. The ruling party eliminated Edward Lowassa; instead, John Magufuli was elected. Following the elimination of Edward Lowassa, it led him to abandon his party and joined the opposition coalition (UKAWA) where he was appointed a flag bearer against his former party.

\subsection{Statement of the Problem}

Previous studies have presented the effects of media framing on audiences. They have stated that during election campaigns the media through "media framing" play a significant role in deciding what audiences should think about and how they should think about campaign issues or agendas (Simon, 2000; Cook, 1998; Yaser, Mahsud \& Paracha, 2014). On the contrary, there are some scholars (Cappella \& Jamieson, 1996; Moy \& Scheufele, 2000) who are still hesitant on the power of the media on audiences. Proponents of this school of thought are of the opinion that individuals as human beings are not so dull to accept any content from the media, instead, they can either accept or reject some of the media information and sometime they strive to look for other sources of information. The focus of this study was to explore the relationship between media agendas vis-à-vis audience agendas in the 2015 general election in Tanzania. The target was to assess if there would be any similarities or correlations between the media agenda and audience agenda. It was assumed that the higher would be the similarities of the agenda the higher would be the influence of the media on individuals, likewise the lower the similarities of the media agenda verses audience agenda, the lower the influence of the media on individuals. To explore this, a content analysis of eight newspapers was done during the 2015 general election campaign in Tanzania. Besides that, a total of 667 questionnaires were distributed in order to explore the major agendas considered by the audiences. 


\section{Literature Review}

\subsection{How Media Framing Works}

It has been reported that during election campaigns, the media play a significant part in informing the public or audience about the election process, including the main agenda and campaign issues. One of the ways through which the media influence voters during elections is through frames in text (Wojdynski, 2008). Frames in text are manifested by the presence of certain keywords, stereotyped images, sources of information, and sentences that provide thematically reinforcing clusters of facts judgments which are presented by the media with an intention of persuading voters towards a certain candidate of political party. The other way which the media can influence prospective voters is the pitch of news items whereby candidates are presented in the media in either a constructive or unconstructive manner of which it is likely that the prospective voters perceive such candidate in a similar manner (Prison, 2003, Hopmann, Vliegenhart \&Albak, 2010). Furthermore, the manner in which an issue is framed (described) and presented by the media in a context, it may profoundly influence individual's voting preference (Thomson, 2006). Thomson says, the way in which a story is written or the terms or choice of words in a news story during an election can send cues to the prospective voters about what stance they should hold on that issue in relation to the candidates and the election process as a whole.

Moreover, there are some elements which help individuals to perceive media frames or how the media influence voters. Chang (2009) says, the language used by the radio, televisions, and other media outlets help audience to remember information and acts to transform the way in which audiences view situations. For example, the use of contrast- to describe a subject in terms of what it is not, spin- to talk or report about a concept so as to give it a positive or negative connotation, slogans- to frame a subject in a memorable and familiar fashion and so on. However, there are some devices which are used to present the media news to the prospective voters and it is these devices that shape on the voters' perception of issues during election campaigns. D’angelo \&Kuyper (2010) mentions some of these devices as; linguistics structures such as; metaphors, visual icons and catch phrases that communicate frames. These devices and other devices are commonly used by the media to describe news items which suggest frames for the audiences towards the communicated information regarding the election.

Likewise, Yates (2012) affirms that during political campaigns coverage, the media tend to concentrate on the secondary qualities of candidates and exaggerate political personalities of candidates. The media normally does influence the directions of public opinions, it holds the capacity to influence the tone of political discourse and the criteria voters employ to make decisions (Cartee, 2005). In many cases, the media has been able to influence voters voting preferences. For example, during the 2008 presidential election in US, Baraka Obama received enthusiastic and positive media coverage possibly leading to similar exaggerations that benefited Obama's victory (Cartee, 2005). Barack Obama has made social networking a basis in the organization of his two electoral campaigns in 2008 and 2012. The 2008 election was the first election where candidates have used social media tools such as Facebook and Twitter (Wooley, Limperos \&Oliver 2010, Beuer, 2004). Moreover, Kuyper (2002) points out that the media through agenda setting function helps to explain how press interacts with political discourse and public perception of the discourse. Kuyper says that news coverage that implies politicians' responsibilities for situations at national level encourages viewers to attach more importance of their performance when evaluating their performances, thus the media is capable of bringing up issues for the public to focus at and eventually open up several interpretations or debates amongst them.

Furthermore, Son (2003) examines the 2000 US campaign coverage, opinion, and the media and he confirms that both salience and framing of candidates influenced their percentage level of polls at the aggregate level. Son adds that, at the individuals' level, the study confirms the effects of media on candidates' salience. Rhee (1997) also confirms that frames from the media particularly print media affect the audience frames during campaign coverage, as well as their voting preferences. During election campaign, the coverage of the print media normally tends to report candidates in such a way that prospective voters are able to evaluate candidates before they make up their voting preferences. Valentino (2002) also examined the framing effects of the media on political participation and he confirms that the media have significant influence on audience framing and perceptions of issues which usually influence their voting preferences. Furthermore, it is noteworthy that most of voters are informed and educated about politics and election issues through the media, more especially the main stream media (Schulz, 1994), and social media (Mazzoleni \&Schulz, 1999). This is very relevant especially when it comes to the coverage of political parties during elections since majority of prospective voters do hear and view the candidates only in the media and rarely in person. There are somewhat reasons to justify that the media has an effect on voters' perception of parties and their candidates during election and voting preferences (Hopmann, 2013, Weaver, 1996). Most of the political parties are informed of the rhythm and the desire of the public on social media timelines that is why more and more politicians are realizing the importance of social media as an electoral instrument (Wallsten, 2007). The young people who are in most cases the potential voters seem to get political information from social media more than any other age group. It is thus becoming clear that online tools play a significant role in shaping public opinion and setting political agendas especially during campaign periods (Wallsten, 2007, Wooley, 2010). Politicians, citizens and journalists increasingly adopt new social media like Twitter, Facebook and YouTube to support their political purposes, be it to involve with other stakeholders in the political public sphere, campaign, publicize or retrieve information, or contribute to rational-critical debate (Bruns, 2014). Social media opens up new paths of inspiration and speech. They have a role, increasingly significant, in the direction and understanding of political behaviour. Online social networks are a contemporary approach to preserve well-informed of political affairs 
(Hanson, 2010). Politicians pursue progressively to adjust their messages to these new apparatuses to reach an audience that can be prospective voters. Political leaders are aware that media have an effect on the vote's conducts that is why they attempt to present a constructive media image (Hanson, 2010).

\section{Types of Media Framing}

Many scholars have written about the types or forms of media framing, for example Oates, Kaid \&Berry (2010), Saunders (2006), Mauro (2001), Robert, Hammond \& Sulfaro (2012), Seib (2008), Chang (2009) have mentioned the followings as some of the types or forms of media framing:

\subsection{Thematic frames}

The thematic frames are the frames which focus on the big picture where the information is well narrated by providing statistics, expert analysis and other newsworthy information to help the audience view the event in a broader context, in other words, it is a way of telling the story that makes it understandable and accessible to the audiences. This type of media framing is actuated by the focus through which the mass media wants the audience to understand the news items. In other words, the thematic framing is characterized by the way through which the mass media uses diverse techniques in telling the audience on what to think about an issue. Since the media has the power of telling what people should think about or what to think about, during election time, the media can be used by politicians to frame news items in such a way that may lead the prospective voters believe what the media reports. For example, the media might use exaggerated statistics to show the audience that a certain candidate is leading.

\subsection{Horse-race frame}

Horse-race frame mainly focuses on the evolution and development of the campaign as a race among aspirants. For example, it reports on who is leading and who is behind in the polls. It does not give any descriptions, explanations or present stories in a broader manner. This coverage has been blamed by scholars claiming that it leaves out voters with little quality information on which to base their votes. In other words, the horse race framing is another technique through which the media uses to drive audience in their preferred focus. Normally such a reporting is written in such a way that the mass media tries to shape the minds and understanding of the audience to concentrate and believe what the media has informed them. During an election time, such horse race framing can be used by the mass media in favour of a given political party because the media may use false or exaggerated figures to show that a given political party or candidate is leading in the voting polls. Sometimes, the mass media may conceal some important facts about a given candidate with an intention of weakening such a candidate during an election campaign.

\subsection{Personality frame}

Personality cantered frame is the tendency of the media to give more preference to individual characteristics and to adopt human interest angles in events while downplaying political considerations. It presents an event in such a way as to attribute responsibility for its cause or solution to either the government or to an individual, the media may decide to assign blames to an individual or organization. It can also be used by crediting or blaming certain political party or candidate. This type of media framing is actually focused at informing the audience about the individual characteristics of a candidate if it is during election. In other words, the media may use such framing in boosting or side-lining or weakening a given candidate. For the example, the media may decide to convince the audience that a given political candidate is corrupt or trustworthy by frequently reporting on the personal characteristics while ignoring the pledges made by such candidate.

\subsection{Episodic frames}

In this kind of coverage, the media usually report and concentrate on current events; it is an event-oriented and is referred to as event cantered reporting where facts are reported in a more descriptive and more meaningful flow. Likewise, episodic frames focus on the immediate event or incident and give little or no context about underlying issues or context. In other words, this type of framing is somewhat focused at informing the audience of every development in the election process which the media believe to be of worthy to be known to the audience. During election time, the media normally covers and informs the audience every fact and or issue in a more meaningful and understandable manner. For example, if the candidate promises to create employment in the country, the media may try to report in such a way that the audience would understand the nature and types of jobs thought to be created. Sometimes the media might use or interview experts to explain more about that subject matter. This type of media framing is actually focused at presenting the news items in a more comprehensive way in order to help audience have a neutral and informed voting decision when it is during election time.

\subsection{Conflict frames}

Conflict frames, it emphasizes conflicts between audiences, groups or institutions as a means of capturing audiences' interests. This type of media framing is used when the media wants to shape the minds of voters about a given candidate or political party. During election period, when the media need to weaken a particular party or candidate, it would normally focus 
at reporting or associating such a candidate or political party with some conflicts. This is one of the media framing technique which politicians and the media do use when they want to weaken their counterparties during elections.

\section{Dimensions of Media Framing}

The dimensions of media framing are categorized into two categories; cognitive attributes and affective attributes (Guy \&Wayne, 2000).

\subsection{Cognitive Attributes}

The cognitive attributes are the types of attributes which involve information about news makers (such as candidates, or other sources). According to Guy \&Wayne (2000), these cognitive attributes normally include; both information about issues (candidate issues) and information about personal characteristics (candidate attributes). Guy \&Wayne (2000) explain that information about news makers (candidate issues) are the issues (such as, moral issues, environment and others) covered, presented, or emphasized by the media about the candidates during the political campaign coverage whereas information about personal characteristics (candidate attributes) is the way how the media relate the candidate issues to the characteristics of the candidate. As process of framing, the media may intentionally concentrate at reporting more on personal characteristic of a particular candidate with an intention of shaping the minds of the audience in such a way that the audience might be forced to perceive such a candidate in such a portrayed manner. Likewise, during election time, the media may equally pay attention of various issues said by a particular candidate or against a particular candidate. In other words, cognitive attributes are the news items or news stories reported about the characteristics of the newsmaker (candidate) and or about various issues connected to a particular newsmaker or simply it is what the mass media writes about the sources of information (newsmakers).

\subsection{Media Affective Attributes}

According to Aparasu \&Bentley (2014), affective is a concept used in the media framing process which mainly addresses affect or emotional tone, such as positive tone, negative or neutral tone, especially in relation to how these tones are selected and assigned or presented in the news coverage; they normally focus on the emotional qualities of the attributes. Affective attributes are generic term encompassing moods, emotions, and evaluations. Affective attributes are the properties, qualities, and characteristics that describe objects, subjects or people in the news and the tone of those attributes or descriptions (Stephen \& Renita, 2006, Wilcox, 2011). According to Kramer (2009), Mckelan (2007) some voters cast their votes based on the affective attributes and or political party identification rather than basing on factual information provided by the media or any other sources of information depicting major campaign issues, candidate's background. Guy and Wayne (2000) argue that affective attributes in media framing are normally characterized by media influence on candidates' affective attributes which involve opinions (posed by the media) about the candidates. Thus, the major components here in the affective attributes are positive coverage, negative, and neutral coverage about the candidates (the tone used by the media in covering or describing the candidates).The tone of the media the coverage normally is confirmed to have similar influence on the audience or public perceptions about the candidates. Guy \&Wayne (2000) states that audiences' who are exposed to a negative or positive tone during campaign coverage, normally are likely to rate or evaluate candidates in the same or similar manner. Generally, the present literatures indicate that there is a great possibility that the media frames during election campaigns play major role in influencing voters' perceptions about candidates. Stephen \&Renita (2006) affirm that research has shown that the media framing through affective attributes reported in the media about news makers such as political candidates do influence the attributes the audience associate with those news makers (candidates). In a nut shell, the affective attributes is the technique used by the journalists or mass media in shaping the minds of the audiences. During election time, the media normally reports various news items about the candidates or political parties (cognitive attributes). In addition to that, the media uses the affective techniques by assigning some tone (positive, negative, or neutral) to the news items or to what they have written about the candidate or political party.

\subsection{Audience Framing}

Audience framing is the mechanisms through which audiences receive and interpret incoming information which they end-up by creating their own meanings (Rasul, 2011). It usually takes place when audiences receive information from the mass media (Pan \&Kosicki, 1993). During audience framing process, individuals do receive information from the media which they carefully assess it, filter it, interpret it basing on their prior knowledge (pre-existing knowledge), emotions, and ethnicity background (Pan \&Kosicki, 1993).). During election campaigns, individuals do use variety of mechanisms to establish their audience framing, among the mechanisms are; pre-existing knowledge, emotions, political discussions, party affiliations and many others (Wang et al, 2000).

\subsection{Pre-Existing Knowledge}

The pre-existing knowledge or simply prior knowledge about candidates and or political parties plays a significant role in the voting preferences among prospective voters. During election periods and voting process in particular, past experiences on the candidates or political parties can impact future voting preferences among voters. Juliusson, Karlsson 
\&Garling (2005) showed that normally past decisions influence the decisions people make in the future elections. It stands to reason that when something constructive results from a choice, people are more likely to decide in a similar way, given a similar situation. On the other hand, people tend to elude recapping past faults (Sagi \& Friedland, 2007). This is significant to the extent that future decisions made based on past experiences are not necessarily the best decisions (David, 2013, (Scheufle, 2001). The inference here is that during election period, normally voters tend to evaluate candidates basing on the past experience and records in their past leadership or paths and that if a candidate is revealed to have an excellent record, such candidate is likely to be supported by people and if the candidate has a bad record people are likely to be sceptical in voting for him. Pre-existing evaluations on the candidates seem to condition the assessment of new information so that prior affect is improperly updated. Thus learning something wicked about a liked alternative often generates a stronger preference for the alternative than existed before the new information was acquired (David, 2013). At some point a voter who meets adequate destructive information about a previously liked candidate or respectable stuff about a disliked one may finally adjust global evaluations to be more in line with reality (Sagi \& Friedland, 2007). Studies (David, 2013) show that during elections, voters stick to their existing affect, at least for a while, motivated reasoning suggests that when an initial evaluation of a candidate is established, that evaluation acts as an anchor against which any new information has to struggle to be accounted for properly. Thus, voters are seldom unwilling to accommodate any new incoming information about the candidates or political parties; they rather appear to evaluate the candidates basing on the prior information. Personal experience is believed to be more important for oneself than for other people. People tend to believe their own picture of politics is more dependent on personal experience and those others' political attitudes are more dependent on mass media or people in their social environment (Scheufle, 2001).

\subsection{Emotions}

Emotions are the affective state of consciousness which comprise of joy, sorrow, fear, hate, or the like experience (West, 2007). It can also be any strong agitation of the feelings actuated by experiencing love, hate, or fear, and usually accompanied by psychological changes, as increased heartbeat or respirations and often overt manifestation, as crying or shaking. Previous studies (Marcus, 2007, Christopher, 2013) have revealed an extensive variety of studies which have been able to establish that the way people act is influenced by the emotions they experience in their lifespan. Among the earliest studies which indicated that feelings like pride and hope, or anger and anxiety, had an impact on people's choices in elections is traced back to the 1980s (Abelson, et al, 1980, Marcus, 1988). During elections, emotions play significant impact on the voting preferences among (Christopher, 2013). Some voters make their voting preferences basing on their love, hate, or moods (emotions) about the candidates or political party. Campaign emotions can be described as to how candidates connect with voters especially during campaign period (Marcus, 2007). Voters implicitly use their feelings towards candidates to organize and effectively simplify their judgment tasks involved in the voting process (Christopher, 2013). Campaigns that elicit angers or enthusiasm may have the behavioural consequences of elevated political participation, whereas campaigns that elicit sadness fear or threats would automatically demoralize participation especially during the voting process (Lau \&Redlawsk, 2006). Emotions shape voters' choices both directly and by guiding the cognitive process leading to voting preferences (Lee, 2000). Sometimes the emotion of love to candidates, joy pride, anger, hate, sadness have great influence in the voting preference making among some voters. Emotions affect electoral decisions in a dual approach; the first approach is the positive emotions which carry the aspect of enthusiasm which directly influence citizens' feelings about the candidates involved and thereby indirectly influence the direction of their vote decisions (Marcus \& MacKuen, 1993, Marcus et al., 2000). The second approach is the dimension of emotion, which the authors label it as anxiety which determines to what extent citizens rely on habitual behaviour. Voters who are less emotionally and or politically sophisticated rely heavily on emotional responses in processing cognitive information in the vote choice process. Weber (2008) argues that emotion elicited in the election campaign has significance influence on how people would think about the campaign issues and the candidates, and this would possibly have impact on the voting preferences among voters.

\subsection{Political Discussion}

Political discussions during elections are vital fundamentals of democratic societies in which citizens are anticipated to make informed voting preferences with regard to issues of civic importance (Himelboim, 2009). Scholars have documented that a few influential individuals play a critical role in mediating this flow of information between mass media and the prospective voters. Smith (2008) argues that citizens discover and form opinions not from pure psychological factors or merely associating with a group, but from discussions, conversations, and interactions with other citizens succinctly puts it, and that it is through these networks that political communication and voting preferences can occur. Apart from the face-toface or verbal discussions, political discussions have now shifted in large numbers to computer-mediated discussion, spaces like Usenet newsgroups, web boards, and e-mail lists (Levine, 2000). The Internet has been a cause for excessive interest among those who appreciate that it gives a big population access to an inclusive range of sources of information and gives each person the likely to create new information or nominate new topics for public discussion which normally influence their voting preferences (Himelboim, 2009). Anderson (2008), asserts that peer interactions and discussions that take place on social media networks and some other forms lead to a situation of identification for the first time voters, namely, the need for the first time voters to 'identify with others' and the 'need to maintain relationships with others', this type of relationship does 
influence even in their voting preferences during elections. Rebecca (2005) notes that the information that prospective voters get through political discussion with friends or other people play an essential influence in their voting preferences because such information allows them get access to diverse and controversial issues about the candidate which sometime can never be discovered by the media. The modes of interaction in the political discussions is more friendly and flexible than in the media, thus people are able to utilize their time to dig-up for more explanations on issues being discussed, it is such patterns of information which influence voters in their voting preferences (Owen, 1999). In brief, political discussions as noted in this segment, is also considered to have influence in the voting preferences among voters. The modes of discussions as noted in this segment is mainly done through face-to-face or through the social media (the internet) where prospective voters normally share information about the candidates and or political parties.

\subsection{Party Affiliation}

Party affiliation is a situation whereby a person is a follower or is a member of a certain political party. Rebecca (2005) defines political affiliation as the attitude of a person considering him/ her to belong to a certain political party. It is suggested that when a person is a member or is affiliated to a political party or if such an individual is a strong supporter of a given political party, such person will normally tend to be loyal to his/her party. In progressive democracies, citizens' attachments to a party strongly influence their political behaviour. Party attachments often define not only how people vote, but also how they evaluate their government (Bartels 2000). Party affiliation has been noted as one of the major factors which influence the voting preferences amongst voters. According to Chiu (2002), party affiliation in American politics is very high among American voters. During elections, party identifications are one of the most consistent determinants for predicting the voting preferences among voters as well as the outcome of the results. It is noted that majority of American voters do identify themselves as either Democrats or Republicans, and most loyally vote for their party's presidential candidates (Chiu, 2002). The influence of party affiliation in American politics is also summarized by (Bartels, 2000) who displays that; the level of party affiliation voting in 2004 was 4\% higher than in 1996, in 2008 presidential election it was quite high, although it was lower than in 2000, 2004, and 1996. According to Bartels (2000), voting preferences among voters in the 2004 presidential election and the 2006 congressional elections have still emerged as the new high points in party affiliation voting among American voters. In general, the influence of party affiliation among voters is reported to be among the influencing factors in the voting preferences. It is noted in the existing literature that sometimes party affiliation can move from an individual level to an institutional. At the institutional level, some media houses whose founders are either politicians or political parties; their coverage has normally been dictated by the party they belong. In Tanzania for example, Tanzania Times is a media house owned by the main opposition leader, Uhuru Publication house which is owned by the ruling party, Sahara Media, Habari Cooperations are owned by politicians. It is this type of party affiliation which is presented in the current literature.

\section{Methods}

In order to explore the audience agendas, the study utilized self-administered questionnaires whereby prospective voters were asked to list down all the campaign agendas during the 2015 election campaign in Tanzania. The question types used in this study were the demographic questions; rating scale (likert scale) questions, and open-ended questions, however, the likert scale questions contained majority of the questions. Five research assistants were recruited to help the administering of the questionnaires to the household of respondents. The sample size for the study was 700, thus, a total of 700 questionnaires were distributed but due to some reasons only 667 were successfully used in the analysis. A systematic sampling technique was used to get the sample. This is because the sample was obtained from the lists of registered voters which was available in the voter's registration books at ever ward. For the case of newspapers, a simple random sampling technique was used to select the eight newspapers (The guardian, Daily News, Mtanzania, Mwananchi, Nipashe, Uhuru, and Habari Leo). All eight selected newspapers were on daily published newspapers. The units of analysis during the content analysis were all the campaign issues/agenda published in the hard news, feature stories and editorial comments. Thus, all agenda/ issues which appeared in the eight newspapers during the one month campaign (September 23-October 23, 2015) period were recorded in a logbook before being analyzed. A total of 84 agendas were recorded from the newspapers.After data collection, the survey data were entered in SPSS version 20 where all necessary cleaning was done to detect missing observations, outliers, and other inconsistencies; including the coding process. Likewise, data obtained from the newspapers were also entered in SPSS, cleaned up and were assigned some codesas well before the analysis. A simple frequency analysis was used to establish the hierarchy as well as the relationship or correlation of the most appearing agenda from both newspapers and individuals. In order to clearly detect the relationship between the media agendas and audience agenda, the study listed down in descending order all the agendas covered by the media against those mentioned by the audience. In order of hierarchy from both media and audience agendas, the study picked and compared the top five agendas from both sides so as to detect if there was any relationship between media and audience agendas.

\section{Research Finding and Discussion}

The findings revealed that there is very slight relationship between media agendas and audience agenda during election campaign. Thus, there is no direct relationship between media framing and audience framing. The finding show that provision of social services was the major agenda which was ranked number one by prospective voters whereas provision of 
free education was recorded number one agenda from the content analysis. The finding showed that 341 out of 667 (51\%) respondents ranked provision of social services as number one agenda whereas 16 out of 84 agendas from the newspapers reported on the provision of free education. Thus, this finding informs us that the media did not have any significant influence on audiences. The finding also show that provision of free education was ranked as number two agenda by the audience whereas corruption was recorded as the second prominent agenda from the newspapers. It was revealed that 120 out of 667 (18\%) respondents considered provision of social services to be the second prominent agenda in the 2015 election whereas 11 out of $84(13 \%)$ newspapers agenda was recorded as the second prominent agenda. This finding also confirms that during the 2015 election in Tanzania, audience did not rely only on the media as their sources of information. It was discovered that most of the audience got political agenda direct from attending campaign meetings and through political discussion with colleagues. Moreover, patriotism was ranked number three by the audiences against the provision of social services which was recorded from the content analysis. It was revealed that 36 out of $667(5.4 \%)$ respondents ranked patriotism as third prominent campaign agenda in the 2015 election in Tanzania whereas 7 out of 84 newspapers agenda ranked provision of social services as third prominent agenda. This finding also further informs us that there was no direct relationship between media agenda and audience agenda during the 2015 election in Tanzania. Likewise, the finding portray that employment was ranked number four by the audience against poverty reduction from the newspapers, and construction of industries was ranked number five by the audience against government reform from the newspapers. It was revealed that 34 respondents (5.1\%) ranked employment as the fourth prominent campaign agenda whereas $6(7.1 \%)$ newspapers agenda reported poverty reduction as number four of the campaign agenda. Lastly, construction of industries was mentioned by $33(4.9 \%)$ respondents as firth prominent campaign agenda during the 2015 election in Tanzania against 5 (6\%) newspapers agenda.

\begin{tabular}{|c|c|c|c|}
\hline Audience Agendas & Ranking & New spaper Agendas & Ranking \\
\hline Social services & 1 & Education & 1 \\
\hline Education & 2 & Corruption & 2 \\
\hline Patriotism & 3 & Social services & 3 \\
\hline Employment & 4 & Poverty reduction & 4 \\
\hline Industries & 5 & Government reform & 5 \\
\hline
\end{tabular}

Table 1: Comparison of Audience and Media Agendas

Overall, this finding informs us that there is no direct relationship between media agenda and audience agenda during political campaigns. The finding shows us that during election campaigns, people do not only rely on the media as their main source of information, instead they do use other political plat forms. In Tanzania, it was revealed that during the 2015 general election, majority (58\%) of individuals got the campaign agenda direct from attending to campaign meetings (rallies). The second source of campaign issues/ agendas was political discussions (23\%). During the 2015 election in Tanzania political discussions played a significant role of information the audiences on the major campaign agenda. This is where people, friends, family members, and colleagues who met in public places, public transports, social gatherings such as funerals, birthdays, and other gatherings whereby they discussed all major campaign agendas or issues. Thus, the media did not act as the main source of campaign agenda during the 2015 election in Tanzania though it had some minimal contribution. Only nineteen (19\%) percent of respondents accepted to get the campaign agenda from the media, specifically television. They said that they did not have enough time to attend political rallies so they watched the rallies and news from televisions. Furthermore, this finding reveals that the media is not the only major source of information through which people get to know campaign issues, instead, politicians and other political stakeholders should use different techniques of selling their campaign agenda or issues to their prospective voters. Looking at the 2015 general election in Tanzania, it appears that only education and provision of social services were learnt from the media but the issues/ agenda of corruption, poverty reduction, and government reforms were learnt direct from campaign meetings or rallies.

\section{Conclusion}

The general findings from this study have revealed that the effect of the media through media framing depends very much on audience framing. This is because audiences do not only make decisions basing on the incoming information from the media, likewise, human beings are selective in nature so they can as well be selective in all incoming information from the media, hence, they can accept or reject some media information basing on their pre-existing knowledge, affiliation, religion, gender, or emotions. This finding is quite surprising and novelty because it challenges majority of previous studies which have reported on the power of the media on audiences' perception on issues and agendas during campaign periods as notes. It thus agrees with Cappella \& Jamieson (1996), and Moy \& Scheufele (2000) who have also questioned the power of the media on individuals.

\section{References}

i. $\quad$ Alsamydai, M. (2013). Basic Criteria for the Success of the Electoral Candidates and their Influence on Voters' Selection Decision. Advances in Management \& Applied Economics, vol. 3, no. 3, 2013, 
ii. Aparasu, R. R. \& Bentley, P. (2014). Principles of Research Design and Drug Literature Evaluation. New York: Pharmaceutical Publishing Press.

iii. Bartels, L. (2000). Partsanship and voting behaviour. American Journal of Political Science, 41(1), 35-50.

iv. Beuer, J. C. (2004). Statistical Analysis for Decision Making and Evaluating Critical Information in Changing Time. New York: Taylor \& Francis Group.

v. Bruns, A. (2014). Media innovations, User innovations, societal Innovations. The Journal of Media Innovation, 1(1), 1327.

vi. $\quad$ Cartee, K. S. (2005). News Narratives and Framing. Massachusetts: Rowman and Littlefield Publishers.

vii. Chang, S. H. (2009). The influence of Media frames on the Public's Perception of Biofuels. A thesis submitted to Graduate Faculty: Iowa State University.

viii. Chiu, K. (2002). An exploratory study on the relationship among electorates voting behaviour, party identification, personal values, and demographic characteristics. PhD thesis submitted to the College of Administration and Business, Louisiana Technical University.

ix. $\quad$ Christopher, W. (2013). Emotion, Campaign, and Political Participation. Political Research Quarte, 66(2), 414-428.

x. $\quad$ D'Angelo, P. \& Kuyper, J. A. (2012). Doing news Framing Analysis: Empirical and Theoretical Perspectives. Chicago: Routledge.

xi. Entman, R. M. (1993). Framing Towards Clarification of Fractured Paradigms.Journal of Communications, 43(4), 51-58.

xii. Gahnström, C. (2012). Ethnicity, Religion and Politics in Tanzania: The 2010 General Elections and Mwanza Region. University of Helsinki

xiii. Goffman, E. (1956). The presentation of self in the every day life. Edinburgh: The University of Edinburgh.

xiv. Goffman, E. (1974). Frame Analysis: an easy on the organization of Experience. Boston.

xv. Grant, A. E. (2001). Framing Public Life: Perspectives on Media and Our Understanding of the Social World. New Jersey: Lawrence Erbaum Associates, Inc; Publishers.

xvi. Guy, G. \& Wayne, W. (2001). Second Level Agenda Setting in New Hampshire Primary: A comparison of Coverage in the three Newspapers snd Public Perceptions of Candidates. Journalism and Mass Communication Quarterly, 78(2), 247-259.

xvii. Himelboim, I. (2009). Discussion catalysts in online political discussions. Content importers and conversations starters. Journal of Computer Mediated Communication, 14, 771-789.

xviii. Hopmann, D. N., Vliegenhart, R. \& Albark, E. (2010). Effects of News Coverage: How Visibility and Tone Influence Party Choice. An Academic Article Presented at the University of Southern Denmark and University of Amsterdam.

xix. Kramer, C. R. (2009). The Emotional Activist: The Role of Affect in Political Decision Making. PhD thesis submitted to the Graduate School of the University of Nebrask.

xx. Kurbas, I (2015).The Factors Influencing Voting Preferences in Local Elections "An Empirical Study". International Journal of Humanities and Social Science Vol. 5, No. 9(1)

xxi. Ladd, J. (2006). Attitudes toward the News Media and Voting Behaviour. Georgetown University

xxii. $\quad$ Lau, R. R. \& Redlawsk, D. P. (2006). How Voters decide, Information Processing during Election Campaigns. New York: Cambridge University Press.

xxiii. Lee, J. (2000). Following One Heart: Emotion and Voting. Austin: PhD thesis submitted to the Graduate School of the University of Texas, Austin.

xxiv. Marcus, G. (2007). The psychology of emotions and politics. Oxford Handbook of Political Psychology, 82 (3), $182-221$.

xxv. McCombs, M. \& Shaw, D.L. (1972). The Agenda-Setting Function of Mass Media. The Public Opinion Quarterly, 36(2), 176-187.

xxvi. McComb, M. (1993). The Evolution of Agenda Setting Research: Twenty Five Years in the Market Place of Ideas. Journal of Communication, 43(1), 58-67.

xxvii. $\quad$ McCombs, M. (2005). A Look at Agenda Setting: Past, Present and Future. Journalism Studies, 6(4), 543-557.

xxviii. McCombs, M. (2003). Agenda Setting Effects of Business News on the public's Image and Opinions about major Corporations. 6(1), 36-46.

xxix. $\quad$ Oates, S., K, L. \& Berry, M. (2010). Terrorism, Elections and Democracy: Political Campaign in the United States, Great Britain and Russia. New York: Palgrave Macmillan.

xxx. Pan, Z. \& Kosicki, G. M. (1993). Framing Analysis. An approach to News Discourse. Political Communication, 10(1), 5575.

xxxi. Rebecca, B. S. (2005). Framing the 2004 Presidential Election: The Role of Media, Political Decision and Opinion Leaders. $\mathrm{PhD}$ thesis submitted to the Graduate Study of the School of the Ohio State University.

xxxii. Robert, R. N., Hammond, S. J. \& Sulfaro, V. (2012). Presidential Campaigns, Slogans, and Platforms: the complete Encyclopaedia. New York: Greenwood Publishers.

xxxiii. Russo, J. E. \& Schoemaker, J.H. (2002). Winning Decisions: Getting the right the First Time. New York: The Doubleday Publishing Group. 
xxxiv. Saunders, A. (2006). The Framing of Candidates: Newspapers, Presidential Hopeful, and the Imaginary Primary. Washington D.C: PhD thesis Submitted to the Faculty of Graduate School of Arts and Sciences of Georgetown University.

xxxv. Seib, P. (2008). Political Communication. Los Angels: Sage Publications.

xxxvi. Smith, L. E. (2008). How Much do Groups Still Matter in Politics? An Examination of Group Influence on Public Opinions. $\mathrm{PhD}$ thesis submitted to the Graduate School of the Clemson University.

xxxvii. Son, Y. J. (2003). Campaign Coverage, Opinion and Media: The Influence of the News Media and the Perceptions of Political Journalists in the 2000 US Presidential Election. PhD thesis submitted to the Graduate School of the Indiana University.

xxxviii. Stephen, B. \& Renita, C. (2006). Network TVs News Cast Affective Framing of the Presidential Candidates: Evidence for a Second Level Agenda Setting Effects Through Visual Framing. Journalism and Mass Communication Quarterly, 83(2), 313-328.

xxxix. Thomson, M. L. (2006). Agenda Setting and Framing: How Politically Slanted Media Affect the Public. PhD thesis submitted to the Graduate School of the Central Missouri State University.

xl. Weaver, D. (1994). Media Agenda Setting and Elections: Voter Involvement or Alienation? Political Communication, 11(3), 347-356.

xli. Weber, C. (2008). The emotional campaign: How emotions influence political behaviour and judgement. PhD thesis submitted to the graduate school, Stony Brook University.

xlii. West, M. (2007). Feelings, Being, and the Sense of Self: A New Perspective on Identity, Affect and Narcissistic Disorders . London : Karnac Books Ltd.

xliii. Wilcox, C. (2011). Bias: The Unconscious Deceiver. New York: Xlibrix Corporation.

xliv. Wojdynski, B. W. (2008). Multimedia Framing in US Newspapers' online Coverage of The Iraq War. PhD thesis submitted to the School of Journalism and Mass Communication. University of North Carolina.

xlv. Wooley, J. K., Oliver, M. \& Limperors, A.M. (2008). The 2008 Presidential election: A content analysis of users generated political Facebook groups. Mass Communication and Society, 13(1), 631-652.

xlvi. Yates, H. E. (2012). Their Minds will follow: Examining the role of Voters' Emotions when formulating Attitudes on Campaign issues in 2004 and 2008 Elections. PhD thesis submitted to the graduate school, university of Kansas. 